\title{
Breaking up with Jesus: A phenomenological exploration of the experience of deconversion from an Evangelical Christian faith to Atheism.
}

\section{Karen Adriana Lee and Peter Madsen Gubi}

\begin{abstract}
This study examines the experience of deconversion from an Evangelical Christian faith to Atheism in the UK. Semi-structured interviews were conducted with six participants and the data were analysed using Interpretative Phenomenological Analysis. The resulting superordinate themes emerged: Process of Deconversion; Post Deconversion Issues; What Helped and Did Not Help. The findings are supportive of similar research conducted on deconversion but are from a UK, rather than from a largely American, perspective. The underlying reason for deconversion is found to be cognitive dissonance and, as such, deconversion is a rational and intellectual process. Helping professionals need to convey a non-judgemental attitude, being understanding, sympathetic, supportive and kind.
\end{abstract}

\section{Key words}

Deconversion; evangelical; atheist 


\section{Introduction}

Deconversion is the process of moving away from a particular religion to a different religion or no religion. In this research, deconversion from an Evangelical Christianity to Atheism is examined. This study focuses on those who have been classified in existing literature as 'secular exiters' and 'true apostates' (Brinkenhoff \& Mackie, 1993; Streib \& Keller, 2004). The aim of this study is to phenomenologically explore deconversion as an experience by seeking to understand the psychological and social consequences of deconversion, both during and after the process. Participants' experiences of seeking help and support through their transition to non-belief were explored to discover what was, and wasn't, helpful. Understanding something of this process may inform therapists and other helping professionals who work with deconversion issues.

The context of this study is the UK, whereas previous research has been conducted in the USA. The research question was: What is the lived experience of deconversion from Evangelical Christianity to Atheism in the UK? The aims were to discover what the social and psychological consequences of deconversion for the individual are; and what the participants' experiences of seeking help and support through the deconversion process were, to ascertain what was, and was not, perceived as helpful.

There are some studies (e.g., Brent, 1994; Bahr \& Albercht, 1989; Buxant \& Saroglou, 2008; Davidman \& Greil, 2007; Fazzino, 2014; Herzbrun, 1999; Jacobs, 1987; Moyers, 1994; Smith, 2011; Zuckerman, 2012) that explore the psychological experience of deconversion from various religious traditions. These studies have shown that loss of faith can be a difficult part of a person's life. They show that deconversion is usually a gradual process and that it is one that can involve significant spiritual struggle, with emotional and social difficulties. However, deconversion can also be beneficial (Altemeyer \& Hunsberger, 1997; Marriot, 2014; Noland, 2016; Ross, 2009; Zuckerman, 2012), enabling a sense of liberation and a valuing of life 'now'. Some studies (e.g., Brent, 1994; Fazzino, 2014; Ross, 2009; Marriott, 2014) have examined the process of deconversion from the Christian faith. Most agree that deconversion is a gradual process and 
something that is initially very much resisted, and that counselling can be helpful (Moyers, 1990; Noland, 2016; Ross, 2009).

\section{Method}

Ethical permission was granted by the University of Chester. Adverts were placed online in an Atheism UK Group, on two Facebook groups for ex-Christians and on the website 'ExChristian.net'. Once initial interest was expressed, participants were sent an information sheet, inclusion criteria and consent form. The inclusion criteria were that participants must:

1) have, in the past, described themselves as any of the following: A Born-Again Christian, an Evangelical Christian, a deeply committed Christian; and have adhered to the following beliefs:

a) The Bible is the authoritative word of God.

b) Salvation comes from accepting Jesus into their lives and having a personal relationship with God and Jesus is vitally important.

2) at least for some part of their time as a Christian, been regularly involved in a church;

3) felt at the time that their belief was personal and deeply held, not simply following tradition or attending church because of family expectations;

4) now self-identify as atheist;

5) feel that they completed the deconversion process over 1 year ago;

6) feel they are able to discuss their deconversion at length without it causing them significant, foreseeable distress in order to minimise the risk of harm caused from participation in the research (i.e. non-maleficence);

7) have access to support should they need it after the interview process;

8) be UK citizens;

9) be age 18 or above;

10) be fluent in written and spoken English. 
Six participants who self-defined as 'atheists' responded (see Table 1.).

\section{Table 1. Participants' demographic information}

\begin{tabular}{|l|l|l|l|l|}
\hline Pseudonym & Age & Sex & Ethnicity & Denomination \\
\hline John & 82 & $\mathrm{M}$ & White UK & Anglican/Brethren \\
\hline Rebecca & 28 & $\mathrm{~F}$ & White UK & Pentecostal/Baptist \\
\hline Steve & 45 & $\mathrm{M}$ & White UK & Baptist \\
\hline Katie & 32 & $\mathrm{~F}$ & White UK & Baptist \\
\hline George & 69 & $\mathrm{M}$ & White UK & Anglican \\
\hline Jemma & 24 & $\mathrm{~F}$ & White UK & Baptist \\
\hline
\end{tabular}

Semi-structured interviews were conducted using the following prompts:

1) Your time as a Christian: What did 'being' a Christian mean to you at the time? How and why did you become a Christian? How did you express your Christian faith? How did you feel about being a Christian?

2) Loss of faith: Tell me the story of how you lost your faith, particularly focusing on your feelings and thought processes around that time. Was it an easy process? What was difficult about it? What was this time of your life like for you?

3) Support: Did you seek support whilst you were going through the deconversion process? In terms of support, what did you find helpful and unhelpful?

4) Your current worldview: From your current perspective, how do you feel now looking back on your days as a Christian? How would you describe your current belief system? Is there anything you wish you had had to help you with the deconversion process?

The interviews were audio-recorded and transcribed. Participants were allocated a pseudonym to enable anonymity as far as possible. An Interpretative Phenomenological Analysis (Smith, Flowers, \& Larkin, 2009) was conducted on the data. This method is concerned with personal perception rather than with the formation of objective statements and seeks an insider 
perspective. A small sample size was used to enable an in-depth understanding of the

phenomena. The findings add the voices of the participants, giving the data a rich texture.

\section{Findings}

Three superordinate themes emerged from the data (see Table 2) along with subthemes.

Table 2. Superordinate themes and subthemes

\begin{tabular}{|ll|}
\hline 1. & Process of deconversion \\
\hline 1.1. & Deeply committed Christian \\
\hline 1.2. & Deconversion is a gradual and non-volitional \\
\hline 1.2 .1$. & Partly a subconscious process \\
\hline 1.2 .2$. & Unwanted and resisted \\
\hline 1.2 .3$. & Moment of deconversion as a realisation not a decision \\
\hline 1.3. & The Catalyst - intellectual, emotional/interpersonal, intuitive \\
\hline 1.4. & Cognitive dissonance \\
\hline 2. & Post deconversion issues \\
\hline 2.1. & Damaging doctrines \\
\hline 2.2. & Difficult emotions \\
\hline 2.2 .1$. & Regret \\
\hline 2.2 .2$. & Embarrassment and shame \\
\hline 2.2 .3$. & Anger \\
\hline 2.2 .4$. & Guilt \\
\hline 2.3. & Feeling a fraud \\
\hline 2.4. & Losing world view and identity \\
\hline 2.5. & Positive outcomes from deconversion \\
\hline 3. & What helped and did not help \\
\hline 3.1. & The importance of 'getting it' \\
\hline 3.1 .1$. & You can't understand unless you have been through it \\
\hline 3.1 .2$. & yourself \\
\hline 3.1 .3$. & Discomfort around Christians \\
\hline 3.1 .4$. & Counseed to connect to other deconverts \\
\hline 3.2. & Atheist positive/affirmative help \\
\hline
\end{tabular}

\section{Superordinate theme 1: The Process of Deconversion}

\section{Subordinate theme 1.1: Deeply committed Christian}

Each participant was once heavily involved in their church. John had been a missionary in Africa.

"That was the purpose of my life, to share what I had found was wonderful with the rest of the world". George had held leadership positions within his church. Steve had been a Deacon and church leader. Rebecca grew up in a very committed Christian family and had spent four years as a missionary in Africa. Jemma did "the Lord's work" at a Christian holiday centre. "... being a 
Christian... was the most important thing to me... it was part of my identity". Katie described making a "personal commitment" to Christ as a teenager and "putting everything into this".

\section{Subtheme 1.2: Deconversion is a gradual and non-volitional process}

\section{Sub-subtheme 1.2.1: Partly a subconscious process}

Both Jemma and George explicitly referred to their deconversion as being gradual and outside of their conscious awareness. Jemma stated that "bit by bit, I was saying goodbye to it." George stated that, "This is going on in the unconscious; the brain working this through, ruminating over this, one isn't fully aware one is doing it".

\section{Sub-subtheme 1.2.2: Unwanted and resisted}

Some of the participants tried to resist the deconversion process. Katie described it as a fight: "...you are kind of fighting it at least half the time, because you desperately want to hold on to what you believe, what's giving you purpose and meaning up to this point and it's just slipping through your fingers and you can't hold on to it no matter how hard you try..." John was very clear that he didn't want to give up his faith and had tried very hard to hold onto it. Whilst talking about his final moment of deconversion, he explained: "But I didn't feel like I actually gave up religion as such; I felt more that it was giving me up... So, it was actually recognising what it was, rather than making a decision."

\section{Sub-subtheme 1.2.3: Moment of deconversion as a realisation not a decision}

Steve also stated that deconversion was something that happens to you rather than being a conscious choice. "So once that penny dropped there is no going back. It's not a choice, not to believe, it's more a realisation, a dawning of something..." Katie described how she knew she was no longer a Christian: “....it was a long process and kind of waking up and realising that I hadn't believed for quite a while but I hadn't wanted to admit that to myself..." 


\section{Subtheme 1.3: The Catalyst - intellectual, emotional/interpersonal, intuitive}

Most participants identified a particular moment, or event, that initiated their doubts and questions. Steve's and Rebecca's interviews reflected more of a growing series of small doubts and then one significant catalyst which initiated their search for alternative answers to their questions about Christianity. For Katie, Jemma and Rebecca, it was an emotional/ interpersonal catalyst which started the questioning. For Katie, it was the death of her mother that gave her "...permission to start asking questions..." (about the truth of her faith). For Jemma, it was "seeing the cracks in people's behaviour" (i.e. people not living-up to what they preached) that triggered her doubts. Rebecca's family fiercely objected to her having a non-Christian partner and said "manipulative things". During this period of family conflict, her father died and although she felt she was already "on the path" to deconversion, she described this as a "one of the turning points". The Christian explanations made no sense or were hurtful and turned her away from Christianity. The initial catalysts for George and John were intellectual in nature. They both located the initiation of their questioning in their time at bible college where they first delved more deeply into Christianity. Steve's deconversion appears to be initiated by strongly intuitive factors. He explained: ".... a large and accumulating number of things where really my reality, what I was experiencing didn't line up with what I saw the bible says should happen". The "final crack" for Steve was the painful and premature death of two men in his church for whom prayer made no difference.

\section{Subtheme 1.4: Cognitive dissonance}

All participants described a period of cognitive dissonance that led to their deconversion, which took the form of an increasing conflict between their Christian beliefs and their reality. "You get this thing where you can hold it all together for so long, but you are increasingly trying to fill in the cracks" (Steve). Jemma gave a very clear depiction of cognitive dissonance at work whilst describing her struggles to incorporate what she had been taught to believe, with her own experience and feelings. "...I couldn't make myself believe that [being gay is wrong]... I was very 
conflicted... it just meant I was all like, twisted, 'cos none of it fitted together really. So, that was a bit of a difficult time".

\section{Superordinate theme 2: Post Deconversion Issues}

\section{Subtheme 2.1: Damaging doctrines}

Some of the participants spoke about elements of Christianity that they found damaging or that had affected them negatively. Rebecca described her time in Africa as a child as "terrifying" and "damaging". Her parents told her that there were evil spirits around in the sky when the local witch doctor was performing rituals. She explained that these experiences along with the religious atmosphere in which she grew up led to lots of issues with anxiety and negative thinking. "I was brought up to be in an almost constant state of fear and I think that the religion that my parents knew... is based a lot on fear. It's taken a really long time to reprogram my automatic thoughts so I can think in a slightly more positive way." She also described the culture in her religious community as always critical and pushing you to "improve". "Whenever you are a Christian, you are basically never good enough for God." Other teachings she felt impacted her negatively were not to plan for the future as that was for God to decide; not to take any pride in her own achievements as pride is bad; and "not to think of myself". Jemma described a similar feeling to Rebecca of always being told, or treated like, she wasn't good enough. She identified within this part of Christian culture a sort of vicious circle: “...it's a trick because that makes you rely on God more because you have such a low opinion of yourself, because people are putting you down all the time, that you are just yearning for God to change you and to make you better and then you are not relying on yourself." She went on to explain that if you are relying on God, once he fails you, then you are left helpless and lost as you don't have other survival mechanisms. Finally, she talked about how Christianity induced excessive guilt and feelings of failure for not meeting the high standards it sets, such as not having sinful thoughts and other things that she felt were impossible to prevent. Steve highlighted Christian teachings on sex and sexuality as "downright unhelpful", and talked about a "constant battle" with some of his own "longings and desires" which 
he was taught he had to hate. He also noticed the manipulation and emotional hype of some church services and was concerned that his children don't "repeat the cycle" he has been through. Katie talked about still having an emotional fear of hell that hits her every so often, even though she can reason her way out of it. For her religious community, the concept of 'spiritual warfare' involving demons and angels was a very real phenomenon. She described frightening moments of sleep paralysis whilst going through the deconversion process, where she awoke unable to move and believing there was a demon in her room.

\section{Subtheme 2.2: Difficult emotions}

\section{Sub-subtheme 2.2.1: Regret}

Katie seemed to be struggling with a sense of regret in wasting many years "believing something that wasn't true". She was torn between wanting to be accepting and philosophical about her Christian past by trying to take the attitude of 'she wouldn't be who she was without those experiences', and having the frustration at having made decisions based on what she thought God wanted her to do according to his "grand plan". Although Steve described his time in Christianity as a "process I had to go through", he also alluded to a desire to go back and "deprogram" himself at age 12 and explain to himself "why not to get into this". He also expressed some regrets at the way he has treated a few people in the past due to (at the time) feeling he was "doing the right thing" in light of Christian teachings. Both Jemma and George expressed the wish that someone had challenged them earlier on in their journeys and made them question their beliefs.

\section{Sub-subtheme 2.2.2: Embarrassment and shame}

Both Jemma and George had a strong sense of embarrassment and shame with regard to their past belief in Christianity. For both, it was related to a frustration with their perceived lack of intelligence in not assessing their beliefs more critically earlier on as Christians. Jemma described her feelings: "And very, very quickly it all seemed very embarrassing, childish and just so obviously not true." George stated, "Well I look back with total embarrassment... That's what 
causes me pain, the shame". They both went on to show understanding for their past selves. George talked about how "vulnerable the brain is to bad ideas" and Jemma recognised that religion is generally a product of childhood indoctrination and faith, not reason. Nevertheless, their embarrassment remained even though they understood why they believed.

\section{Sub-subtheme 2.2.3: Anger}

The 9/11 attacks made George think for the first time about "the wicked potential of religion".

There was a sense that part of his anger toward religion was not only due to obvious atrocities and violence done in the name of religion, but also how it impacted on his own life and development. "It's what this pack of awful ideas does to the brains of people; and it did it to me! It made me behave in a certain way... - how a Christian should behave..." For Katie, there was a sense of struggle over her feelings towards her family. She understood that they had only the best intentions in bringing her up in the faith, and yet she seemed to be struggling with at least some sense of betrayal by them and some frustration on an instinctual level, even though she knew it was unfair to judge them. "There is an undercurrent of, here are people that I trusted telling me that this thing is true when really it's their hope, it's their belief that it's true and it's not necessarily [true]... I can't judge them too harshly, or at least I don't want to. I don't think it's fair to do so..."

\section{Sub-subtheme 2.2.4: Guilt}

\section{Subtheme 2.3: Feeling a fraud}

Steve's wife and children are Christians and are not yet aware of his deconversion. He was concerned about how his lack of belief would affect his marriage. Steve described often feeling "stressed out" due to having to be "undercover" with his non-belief; "... it's the lack of authenticity about being seen as who I really am", that was the most difficult part of the deconversion process for him. Katie felt unable to tell her parents and wider family that she is now an atheist for fear of their reaction and of how it will affect her relationship with them. However, this left her feeling a "fraud" and with a distance between her and her family. As part of her deconversion process she 
has been able to accept that she is bisexual and described her family as "not particularly friendly with gay people, or anyone that is different really". This added a further layer of complication and meant that she had to sit through family conversations where they say "quite hurtful" things regarding gay marriage and similar issues and her only option is to "sort of rage inside". Jemma was also hiding the fact that she no longer believes from her parents. She said that if they knew, it would "break their hearts" and they would think she was going to hell. However, she also explained that it caused her inner conflict as she feels she is not "being true" to herself. Rebecca chose not to hide her deconversion from her family and it caused a lot of stress and conflict. She mentioned her father specifically as being very critical of her life decisions, and that after her father's death, her family continued to say manipulative and hurtful things about how "stressed out" her Dad had been, implying his death was her fault.

\section{Subtheme 2.4: Losing world view and identity}

Katie described how it felt to have her world turned upside down, “...that it is your world view, it's how you understand your place in the world, how you understand the things that happen to you, how you understand what you are supposed to do with your life. And then that all falls apart and you have got to try and find a way of making sense of everything again from a completely different place." She found this a very difficult time, to the point where everything felt "pointless and meaningless" and led to her feeling insignificant in a vast universe. Rebecca went through a stage of feeling quite lost. To complicate matters further, she had been taught not to "question things" and so struggled to think for herself. In order to begin to form her new world view, she found a psychologist helpful in that she was able to "...explore what I actually thought about things and about myself in a safe environment." Jemma described a very specific and poignant moment whilst sitting in work after spending many hours in previous weeks researching evolution, the big bang theory and many other topics about the galaxy. “...I was just feeling so disconnected and so small, 'cos I was having some kind of existential angst - having like my own mini crisis; but no one knew and I was all on my own..." John came to unbelief very gradually and explained: “...what I 
found I was doing was, I was shedding bit-by-bit all the things that made me who I was." He gradually withdrew from church and Christian-based work and re-created what he valued in Christianity within the new sphere of social work. "I was establishing a new persona which was this guy who was actually doing something useful in life for vulnerable people. So, there were many similarities to my previous life but I moved on to a separate field." John's story is one of reinvention and hope, that a new and equally satisfying life can be found outside Christianity.

\section{Subtheme 2.5: Positive outcomes from deconversion}

Jemma talked a lot about the positive changes she felt in herself after being through the deconversion process. She felt she was more her own person now and is more confident in herself and what she believes, and also has her own identity rather than subsuming it under her previous position as "a washed clean child of God". In reference to her stage of cognitive dissonance, she explained how "refreshing" and "relaxing" it was "not to have to do mental back flips all the time, to justify in my own head what I believe." She said she has more inner peace, and there is a sense that her life is now an open book whereas before it was restricted within Christian boundaries. She also enjoys the freedom from the pressure to be constantly trying to "become more like God", and the freedom from guilt for thoughts and other 'sinful' things she felt were unavoidable. Rebecca's story was one of escaping from a religious background that was damaging to her. For her, she could leave her faith behind and "rewire" her brain in a more positive way. She also talked about being a different person and enjoys being more open-minded and accepting. John summed up his immediate feelings upon realising he didn't believe in God anymore as follows: "That realisation ended the turmoil I felt. I experienced a relief and a freedom that I can only describe as what many Christians would say they feel when they become a Christian. People say, 'What a wonderful experience.' For me, to say, I realise that I haven't got God on my shoulder, was a freeing experience."

\section{Superordinate theme 3: What helped and did not help}




\section{Subtheme 3.1: The importance of 'getting it'}

All participants used the phrase 'get it' in reference to truly understanding Christianity and deconversion. They all expressed the sentiment that unless someone has gone through a deconversion process themselves, they are unlikely to understand what it is like, and therefore, most were dubious about a 'non-deconvert' being able to help them fully. For those who wanted help and support with their deconversion, their main priority was to find others who had gone through the same process so they could talk freely without having to explain themselves and free from fear of judgement.

\section{Sub-subtheme 3.1.1: You can't understand unless you have been through it yourself}

Steve put it very straightforwardly: "...if a person was: a) still religious; or b) hadn't been religious, then I doubt very much they would have quite the understanding to understand the world view of the person and what it would mean to the people around them." John explained the difference between talking to someone who 'gets it' and someone who doesn't: "...I would recognise that they [an ex-Christian] would know what I was talking about. If I was to say that I stood on the platform and waved my arms about enthusiastically and led singing of choruses and hymns they'd say, 'What?!'. Rebecca makes it very clear that, contrary to what some people have implied, she is not an "extreme case" and described her family as "every day Evangelical Christians". Jemma corroborated this. In reference to some of her own experiences in Christianity, which her boyfriend regards as "crazy", she responded, "But that's just a regular occurrence that goes on in Christianity all the time. So, it's hard trying to convey what that constantly does to you when you are exposed to that all the time... I think people can be very supportive, but if they don't get it, if they have never been there, then it's just not that helpful..."

\section{Sub-subtheme 3.1.2: Discomfort around Christians}

All participants felt unable, or hesitant, to speak to Christians about their experience because of fear of judgement or being proselytized to. Katie was not convinced that a counsellor who was a 
Christian would be able to be neutral whilst counselling someone who was deconverting: "...and other people would feel compelled to challenge or put their own beliefs across". Rebecca felt that she spent so long dipping in and out of counselling with different therapists because she was afraid they may be religious themselves and so wouldn't understand and might judge her or try and re-convert her. Jemma expressed her unease around Christians even if they appear to be accepting on the outside: "But then you kind of don't know what they are thinking in the back of their heads... they think that you are lost and they pity you, or feel that you can't be as content as they are, or you were never a Christian in the first place..."

\section{Sub-subtheme 3.1.3: The need to connect with other deconverts}

Rebecca described attending an Atheist society which she found helpful, but still she felt different, and "quite lonely at times and a bit stupid" because sometimes they would "ridicule how religious people think", which had been how she thought not so long ago. Rebecca's solution was to set up a 'Recovering From Religion' group, which gathered 5 or 6 other ex-Christians from Evangelical backgrounds, and she found this very helpful as they could all relate to one another. Jemma also made the distinction between a regular atheist and an ex-Christian atheist in terms of what support would be helpful: "There are a lot of atheist meet-ups and secular talk meet-ups, but it's different from someone who has been through a deconversion or religious trauma..." She talked about how it would be great if a committed Christian she knew deconverted so she could connect with them. Steve described being able to connect with other ex-Christians online as "a big release" as he was ready to "explode" just before discovering the group. He too thought it would be "fantastic" if there were face-to-face meet-up groups for ex-Christians.

\section{Sub-subtheme 3.1.4: Counselling experience}

Katie said of her counsellor: "I feel like with my personal therapist, that I am still having to try to make her understand what a huge thing it was." She went on to explain: "There is some sort of: Oh well if you change your mind you can always pick it up again... It doesn't work like that..." This 
lack of grasping what's going on made Katie feel "...there is no point talking about this because she just doesn't get it..." At other times, she tried her best to explain what it was like. Katie explained that in order for someone to be an effective counsellor to someone who was deconverting they would need to be "...someone who had some understanding of how allconsuming a religious belief is and then the repercussions of that when it all starts falling apart. How much that can impact on all areas of your life really." Rebecca had a number of different counsellors and described one of them as "a bit 'iffy"'. Sensing the counsellor's discomfort regarding the deconversion topic, she focused on other issues. She talked about her last round of counselling being particularly effective as she was able to be totally honest with the therapist. She thought that this was due to a combination of factors. Firstly, she realised she wasn't going to heal unless she said everything and also, she talked about getting a "good vibe" off the counsellor. Rebecca talked about her being "sympathetic and non-judgemental" and that after discussing other issues, the counsellor "had been really kind, supportive and understanding". Rebecca talked about how it would have been useful to have a list of secular psychologists and counsellors so she could be assured that they wouldn't try to re-convert or judge her.

\section{Subtheme 3.2: Atheist positive/affirmative help}

All of the participants talked about being helped in one way or another by an atheist or atheist writing. As George was moving away from the church, he met his partner who was an atheist, and this seems to have made the deconversion process much easier for him. In regard to some counselling he had: "Faith and Christianity was never the issue here are all. I think why it wasn't is because my partner has absolutely not one single religious bone in his body... so I had him to bounce off these feelings and ideas. That maybe explains it..." [explains why it wasn't a difficult process]. George also recalled coming across New Atheist authors. He described this discovery as "the beginning of the end"; finding new and more convincing explanations for the universe and different perspectives seemed to extinguish what was left of his belief in God. John spoke about finding sceptics' writings useful. He explained: "I understood critical thinking and the scientific 
method for the first time, and by this time I was well into my 40 s. I think it was a time of enlightenment for me." Jemma talked about support from a strongly atheist friend as being very helpful. "She was very insightful even though she'd never been a Christian herself. She really understood about the whole indoctrination process, saying I shouldn't be embarrassed, and I shouldn't be ashamed of it because it wasn't my fault, because it was almost like mental abuse. I do see it as mental abuse, but not purposeful... It's kind of accidentally mentally abusing somebody... So, my friend was kind of telling me, that that's what's happened to you and you need to accept that and then kind of own it and move on. That helped a lot..." Steve had read a lot of New Atheist literature in order to "form a new world view and understand the world." With his old structure wiped away it was very important to him to find answers he could be confident in. Rebecca talked about joining an atheist society and how refreshing it was to learn about the lots of different views people had. Katie explained how she used particular types of anti-religious atheist YouTube videos to express her anger in a safe way. She explained: “...I wouldn't want to have that same attitude towards anyone really, but it was quite cathartic to watch someone else and go 'Well actually I agree!' and not have to feel like you have to censor your opinions or thoughts..."

\section{Discussion}

Being small-scale and phenomenological in nature, this study is limited in its generalizability. However, it does provide insight into how deconversion can be for some, which may assist helping professionals in having a greater appreciation of how deconversion can impact a person's life. Although gender distribution was equal, all participants were well-educated, having been to university and/or in professional occupations. All participants were Caucasian. It may be that different factors would emerge from the data with a more diverse social class and ethnic representation.

Nevertheless, this study indicates that deconversion is a gradual and non-volitional process. It was not sought by participants nor did they let go of their faith without a fight. This study confirms the personal significance of catalyst events (Brent, 1994; Marriott, 2014). When the catalyst is located after the period of cognitive dissonance (e.g. Rebecca and Steve), it seems to 
be something which triggers off a critical investigation into Christianity, and deconversion happens relatively quickly after that, as they are already open to alternative ideas due to the frustration of the cognitive dissonance period. Although George located his initial catalyst in bible college many years before he finally deconverted, he also talked about a number of poignant events much closer to his deconversion, such as the $9 / 11$ attacks. Everyone who loses faith must have had a first doubt at some point. For some, it is a significant moment that they don't forget, and for others, it could pass by unnoticed. Wherever individuals locate their particular catalyst, or series of catalysts, what is clear is that deconversion doesn't happen until a period of cognitive dissonance has taken place. The catalysts in this study reflect what previous research has discussed in terms of 'reasons for deconversion', and similarly were classified into three themes: intellectual, emotional/ interpersonal and intuitive. The final 'nail in the coffin' for these participants' belief in God was invariably intellectual in nature, through studying scientific knowledge and atheist arguments. Although there may be emotional and intuitive triggers for deconversion, for these participants it was a strongly intellectual and rational process.

A number of participants referred to the impact of damaging doctrines, which in a postdeconversion context, can be seen as both positive and negative. Now that they no longer believe in Christianity, they are free to leave those teachings behind and create their own morality. However, although some participants no longer believed these teachings 'logically', they were still affected on an emotional level by the beliefs they had held for so long. Some doctrines can be seen as conditions of worth which need to be worked through once the belief has gone on a rational level. It may be that, for some, in order to be at peace with themselves they have to move away from religion altogether. Only when religion is removed, can the damaging messages come to light and be challenged, otherwise they remain hidden and legitimized by certain scriptures impressed upon these individuals as children.

The experience of difficult emotions seems to reflect a sense of inner conflict in trying to come to a place of acceptance. Each emotion was juxtaposed with reasons why the participant shouldn't feel guilty/ embarrassed/ regretful etc.; yet those emotions persisted. Anger seemed a 
particularly complex emotion to deal with. Family issues were pertinent for each participant who still has a Christian family. There is again, a real sense of inner conflict - this time between wanting to be true to oneself and a fear of the consequences of being so. Participants discussed issues around loss of world-view and identity, existential issues and the challenges of re-creating oneself and finding new meaning and an understanding of the world. In terms of positive outcomes, freedom in one form or another, is the dominant gain. They also confirm that the benefits of deconversion outweigh the costs.

In terms of being offered support, participants found talking to other people who 'get it' - who understand the enormity, significance and implications of their deconversion for themselves and for their family - as most beneficial. Their choice was to seek-out other deconverts, achieved mainly via online ex-Christian groups. There was a strong desire to be able to meet up face-toface with other ex-Christians in 'meet-up' groups. There are Humanist and Atheist meet-up groups and organisations but, as participants pointed out, ex-Christian atheists are different to other atheists. Nevertheless, atheist groups did have their place. Participants needed help to establish a new world view and affirmation in their new identity. They were helped by atheist and nonChristian friends and professionals who could offer support, affirmation and reassurance. They were also helped by accessing online atheist communities, YouTube videos and articles, and reading books by atheist authors. These resources helped them clarify their own thoughts and opinions, offered a therapeutic outlet for more negative emotions, and gave confidence in their new non-Christian status. If deconverts have Christian family who know about their deconversion, this support becomes even more vital as they may be dealing with a lot of pressure and people telling them they are wrong. The ability to feel confident in their new world view is vital as certainty in one's beliefs, rather than the specifics of those beliefs, produce higher well-being scores (Baker \& Cruickshank, 2010; Donahue, 1985; Riley et al., 2005).

In offering 'helping support', participants reported that they want someone who won't view them as crazy and stupid for having ever believed. Neither do they want someone who will judge 
them for losing their faith and being an atheist. Conveying a non-judgemental attitude, being understanding, sympathetic, supportive and kind, were what was found helpful.

Despite spirituality and religion being vitally important in the lives of many, this research suggests that some people are happier and function better without spiritual beliefs and need to let go of their religion in order to heal themselves. It may be helpful for a client who is dealing with deconversion to know the helper's stance on spiritual matters early on. In this way, clients can make an informed choice as to whether or not they want to work with a helping professional of faith and, if they have no choice, then that the issues around their different perspectives can be dealt with openly, sensitivity and in an accepting manner. It also demonstrates that there is little difference between deconversion experienced in the UK to that which is experienced in the USA.

\section{References}

Altemeyer, B. \& Hunsberger, B.E. (1997). Amazing conversions: Why some turn to faith and others abandon religion. New York, USA: Promtheus Books.

Bahr, H.M. \& Albercht, S.L. (1989). Strangers once more: Patterns of disaffiliation from Mormonism. Journal for the Scientific Study of Religion. 28(2): 180-200.

Baker, P. \& Cruickshank, J. (2010). I am happy in my faith: The influence of religious affiliation, saliency and practice on depressive symptoms and treatment preference. Mental health, Religion \& Culture. 12(4): 339-357.

Brinkerhoff, M.B. \& Mackie, M.M. (1993) Casting off the bonds of organized religion: A religiouscareers approach to the study of apostasy. Review of Religious Research. 34(3): 235-258.

Brent, J. S. (1994). Leaving protestant fundamentalism: A qualitative analysis of a major life transition. Counselling \& Values. 38(3): 205-214.

Buxant, C. \& Saroglou, V. (2008). Joining and leaving a new religious movement: A study of exmembers' mental health. Mental health, Religion and Culture. 11(3): 251-271.

Davidman, L. \& Greil, A.L. (2007). Characters in search of a script: The exit narratives of formerly ultra-orthodox Jews. Journal for the Scientific Study of Religion. 46(2) 201-216.

Donahue, M.J. (1985). Intrinsic and extrinsic religiousness: Review and meta-analysis. Journal of Personality and Social Psychology. 48(2): 400-419.

Fazzino, L.L. (2014). Leaving the church behind: Applying a deconversion perspective to evangelical exit narratives. Journal of Contemporary Religion. 29(2): 249-266.

Herzbrun, M.B. (1999). Loss of Faith: A qualitative analysis of Hewish nonbelievers. Counselling and Values. 43(2): 129-141. 
Jacobs, J. (1987). Deconverison from religious movements: An analysis of charismatic bonding and spiritual commitment. Journal for the Scientific Study of Religion. 26(3): 294-308.

Marriott, R.J. (2014). The cost of freedom: A grounded theory study of the impact of deconversion from Christianity to Atheism. Unpulished PhD thesis. Biola University. Retrieved from https://search.proquest.com/docview/1666812605?pq-origsite=gscholar Accessed [19/02/2019]

Moyers, J.C. (1990). Religious issues in the psychotherapy of former fundamentalists. Psychotherapy: Theory, Research, Practice, Training. 27(1): 42-45.

Moyers, J.C. (1994). Psychological issues of former fundamentalists. Cultic Studies Journal. 11(2): 189-199.

Noland, T.E. (2016). From belief to disbelief: A phenomenological study of the journey from Christian fundamentalism to Atheism. Unpublished MAC dissertation: Athabasca University. Retrieved from https://dt.athabascau.ca/jspui/bitstream/10791/228/3/Journey\%20From\%20Belief\%20to\%20Atheis m\%20v3.pdf [Accessed 19/02/2019]

Riley, J., Best, S., \& Charlton, B.G. (2005). Religious believers and strong atheists may both be less depressed than existentially-uncertain people. QJM: Monthly Journal of Physicians. 98: 840.

Ross, K.H. (2009). Losing faith in fundamentalist Christianity: An interpretive phenomenological analysis. Unpublished MCounPsy Dissertation: University of Toronto. Retrieved from https://tspace.library.utoronto.ca/bitstream/1807/18123/11/Ross_Karen_H_200911_MA_thesis.pdf [Accessed 19/02/2019]

Smith, J.A., Flowers, P. \& Larkin, M. (2009). Interpretive Phenomenological Analysis: Theory, method and research. London: SAGE.

Smith, J.M. (2011). Becoming an atheist in America: Constructing identity and meaning from the rejection of theism. Sociology of Religion. 72(2): 215-237.

Streib, H. \& Keller, B. (2004). The variety of deconversion experiences: Contours of a concept in respect to empirical research. Archive for the Psychology of Religion. 25: 181-200.

Zuckerman, P. (2012). Faith no more: Why people reject religion. Oxford, UK: Oxford University Press.

\section{Biography:}

Karen Adriana Lee, MA, MSc, is a qualified Person-Centred Counsellor and an ex-evangelical Christian.

Peter Madsen Gubi, PhD, ThD, is Professor of Counselling and Spiritual Accompaniment at the University of Chester, UK, and Minister of Dukinfield Moravian Church, Manchester, UK. 